\title{
Triptans in prevention of menstrual migraine: a systematic review with meta-analysis
}

\author{
Yong Hu, Xiaofei Guan, Lin Fan and Lingjing Jin*
}

\begin{abstract}
Randomized clinical trials (RCT) assessing the efficacy and tolerability of triptans compared with placebo as shortterm prophylaxis of menstrual migraine (MM) were systematically reviewed in this study. Triptans, which interfere with the pathogenesis of migraine and are effective in relieving associated neurovegetative symptoms, have been extensively proposed for prevention of menstrual migraine attacks. We searched Cochrane CENTRAL, MEDLINE and EMBASE for randomized, double-blind, placebo-controlled trials on triptans for MM until 1 Oct, 2012. A total of six RCTs were identified. Two authors independently assessed trial's quality and extracted data. Numbers of participants free from MM per perimenstrual period (PMP), requiring rescue medication, suffering from headache-associated symptoms and experiencing adverse events in treatment and control groups were used to calculate relative risk (RR) and number needed to treat (NNT) with their corresponding 95\% confidence interval (Cl). A total of 633 participants received frovatriptan $2.5 \mathrm{mg} \mathrm{QD}, 584$ received frovatriptan $2.5 \mathrm{mg} \mathrm{BID}, 392$ received naratriptan $1 \mathrm{mg}$ BID, 70 received naratriptan $2.5 \mathrm{mg}$ BID, 80 received zolmitriptan $2.5 \mathrm{mg}$ BID, 83 received zolmitriptan $2.5 \mathrm{mg}$ TID and 1104 received placebo. Overall, triptans is an effective, short-term, prophylactic treatment of choice for MM. Considering MM frequency, severity and adverse events, frovatriptan $2.5 \mathrm{mg}$ BID and zolmitriptan $2.5 \mathrm{mg}$ TID tend to be the preferred regimens.
\end{abstract}

Keywords: Meta-analysis, Systematic review, Frovatriptan, Naratriptan, Zolmitriptan, Menstruation, Migraine, Prophylaxis

\section{Review} Introduction

Migraine, a primary headache disorder, is more common in women $(14.5-18 \%)$ than in men $(4.5-6 \%)[1,2]$, and it is often associated with sensory symptoms, nausea or vomiting, and disability $[3,4]$. Female migraineurs frequently experience headache in association with their menstrual cycles [5,6], which is also known as menstrual migraine (MM). MM includes menstrually-related migraine, defined as migraine with menstruation as well as at other times of the cycle, and pure MM, in which migraine occurred only in association with menstruation on or between day -2 to day $+3[7,8]$. MM has been reported to be longer, more disabling, less responsive to acute therapy, and more prone to recurrence than nonmenstrual migraine attacks. Effective preventive strategies are key for the management of MM [9-12]. Rofecoxib [13],

\footnotetext{
* Correspondence: lingjingjin@hotmail.com

Department of neurology, Shanghai Tongji Hospital, Tongji University School of Medicine, Xin-Cun Road 389, Shanghai 200065, China
}

estradiol [14,15], topiramate [16,17], magnesium [18], nimesulide [19] and naproxen sodium [20] have been used in the treatment of migraine.

Triptans, such as frovatriptan, naratriptan and zolmitriptan, are a class of highly selective serotonin receptor agonists, which can interfere with the pathogenesis of migraine and are effective in relieving the associated neurovegetative symptoms [21-23]. They have been recommended as first-line drugs for the treatment of moderate to severe migraine, including MM [24,25]. In recent years, triptans have been extensively proposed for the prevention of menstrual migraine attacks.

To date, no systematic review has been done to investigate the efficacy and tolerability of triptans in the prevention of MM. This review was undertaken to evaluate the efficacy and tolerability of triptans at different doses in randomized controlled trials (RCTs). Our findings may offer an updated reasonable guide for the treatment of MM in clinical practice.

\section{Springer}

(c) 2013 Hu et al.; licensee Springer. This is an Open Access article distributed under the terms of the Creative Commons Attribution License (http://creativecommons.org/licenses/by/2.0), which permits unrestricted use, distribution, and reproduction in any medium, provided the original work is properly cited. 


\section{Methods}

\section{Studies}

We searched the Cochrane Central Register of Controlled Trials, Medline and Embase using the terms "migraine", "migraine disorders", "prevention", "prophylaxis", " menstrual", "menstrually" and "menses". References of identified studies were further evaluated. Clinical trials before 1 October 2012 were collected for analysis. There was no restriction on language, but we focused on studies that had been conducted in humans and RCTs. Two authors independently searched and selected studies, and then extracted data from each study for further analysis. Disagreements were resolved by discussion with another author. A placebo comparator is essential to confirm the effectiveness of triptans, and the comparisons were done between triptan and placebo. MM was diagnosed according to the criteria developed by the International Headache Society (IHS) or other definitions that conformed in general to IHS diagnostic criteria $[8,26]$. There was no restriction on MM frequency, duration or type, dose or route of administration, provided the medication could be selfadministered. Although there are a few studies suggesting triptans are effective in the treatment of MM [27-30], data of these studies were not included for analysis to minimize potential confounder.

\section{Statistical analysis}

Methodological quality was assessed using the Oxford Quality Scale [31]. Studies were analyzed using a single dose of a triptan in reducing the incidence of MM, MM severity, need for rescue medicine and adverse events. The effect of the association was expressed as relative risk (or 'risk ratio', RR) with its corresponding 95\% confidence interval (CI). Pooled RR was estimated using the fixed effects. Heterogeneity between studies was tested using the Q statistic. Such heterogeneity was considered statistically significant if a value of $\mathrm{P}<0.1$ was present [32]. Number needed to treat (NNT) with 95\% CI was used as absolute measures of benefit, termed number needed to treat to benefit (NNTB), or harm, termed number needed to treat to harm $(\mathrm{NNTH})$. The data included in this meta-analysis might differ slightly from those in previous reports because we treated data in a consistent manner across all trials. STATA version 12.0 (STATA, College Station, TX, USA) metan package (version 1.86) was used for meta-analyses.

\section{Results}

Studies which were included in this study for analysis are shown in Table 1.

\section{Studies}

Seven trials that met our inclusion criteria were identified, among which one [37] was excluded because its data were included in one of the remaining 6 trials. All the six trials (Table 1) were double-blind. Among them, Silberstein's trial (2004) was cross-over in design. All of these studies focused on a single dose of a triptan in the prevention of $\mathrm{MM}$ and were multicentred. The mean age of participants ranged from 36 to 38 years, and all were women.

All trials compared a triptan with placebo. No trials directly compared one drug with another. Frovatriptan $2.5 \mathrm{mg} \mathrm{QD}$ and $2.5 \mathrm{mg}$ BID were tested in two trials, naratriptan $1 \mathrm{mg}$ BID in three trials, and zolmitriptan in one trial. In Newman's trial (2001), two doses of naratriptan (1 mg, $2.5 \mathrm{mg}$ ) were administered. A total of 633 participants received frovatriptan $2.5 \mathrm{mg}$ QD, 584 received frovatriptan $2.5 \mathrm{mg}$ BID, 392 received naratriptan $1 \mathrm{mg}$ BID, 70 received naratriptan $2.5 \mathrm{mg}$ BID, 80 received zolmitriptan $2.5 \mathrm{mg}$ BID, 83 received zolmitrip$\tan 2.5 \mathrm{mg}$ TID and 1104 received placebo.

Most trials evaluated the proportion of patients without MM during the treated PMPs as the primary outcome. Three of six trials evaluated the proportion of patients using rescue medication and two evaluated the severity of MM. Two of six trials evaluated the MM duration and MM associated symptoms in distinct ways.

Methodological quality, assessed using the Oxford Quality Scale, was good in all studies. Except Tuchman's trial (2008) which scored 3/5 and Newman's trial (2001) which scored 4/5, all the other trials were scored $5 / 5$.

Table 1 Clinical trials included in this meta-analysis

\begin{tabular}{|c|c|c|c|c|c|c|c|c|}
\hline & Country & $\begin{array}{l}\text { Patients } \\
\text { (n) * }\end{array}$ & Triptan & Dose & $\begin{array}{l}\text { Migraine } \\
\text { subtype }\end{array}$ & $\begin{array}{c}\text { Treatment } \\
\text { duration }\end{array}$ & $\begin{array}{c}\text { Day of } \\
\text { treatment } \\
\text { onset }\end{array}$ & $\begin{array}{c}\text { Consecutive } \\
\text { PMP }\end{array}$ \\
\hline Silberstein (2004) [33] & USA & 506 & frovatriptan & 2.5 mg QD or BID & MAM $^{* *}$ & 6 & -2 & 1 \\
\hline Brandes (2009) [7] & International & 410 & frovatriptan & 2.5 mg QD or BID & MM & 6 & -2 & 3 \\
\hline Newman (2001) [34] & USA & 206 & naratriptan & $1 \mathrm{mg}$ or $2.5 \mathrm{mg}$ BID & MAM $^{* *}$ & 5 & -2 & 4 \\
\hline Mannix (s1) (2007) [35] & USA & 287 & naratriptan & $1 \mathrm{mg} \mathrm{BID}$ & $\mathrm{MRM}^{* *}$ & 6 & -3 & 4 \\
\hline Mannix (s2) (2007) [35] & International & 346 & naratriptan & $1 \mathrm{mg}$ BID & $\mathrm{MRM}^{* *}$ & 6 & -3 & 4 \\
\hline Tuchman (2008) [36] & USA & 244 & zolmitriptan & 2.5 mg BID or TID & $\mathrm{MM}^{* *}$ & 7 & -2 & 3 \\
\hline
\end{tabular}

* intention-to-treat population

** used Headache Society (IHS) 1988 criteria. 
Points were lost due to failure to adequately report the method of randomization and blinding. All studies reported withdrawals or dropouts. Sequence generation, allocation concealment and blinding were assessed using the "risk of bias" tool (Figure 1). No studies were at high risk of bias.

\section{Primary outcomes}

For the primary outcomes of interest, we focused on the proportion of patient free from MM during the treated PMPs. Except Silberstein (2004), all the other trials crossed more than one PMP, and thus being free from MM per PMP was selected as our primary outcome. The characteristics of MM including MM severity were used as secondary outcomes.

\section{Frovatriptan}

Silberstein (2004) and Brandes (2009) tested frovatriptan $2.5 \mathrm{mg}$ QD and BID. The relative benefit of frovatriptan $2.5 \mathrm{mg}$ QD compared with placebo was 1.48 (1.27 to 1.72), giving an NNTB of 7.22 (5.25 to 11.54 ); that of frovatriptan $2.5 \mathrm{mg}$ BID compared with placebo was 1.82 (1.58 to 2.09), giving an NNTB of 3.90 (3.23 to 4.93). Patients with frovatriptan $2.5 \mathrm{mg}$ BID had a $23 \%$ increase in free from MM per PMP 1.23 (1.10 to 1.39), giving an NNTB of 8.50 (5.77 to 16.19), compared with frovatriptan $2.5 \mathrm{mg}$ QD (Figure 2).

\section{Naratriptan}

Three trials (Mannix (s1) (2007), Mannix (s2) (2007), Newman (2001)) tested naratriptan $1 \mathrm{mg}$ BID. The relative benefit of naratriptan compared with placebo was 1.48 (1.20 to 1.83), giving an NNTB of 7.98 (5.24 to 16.71) (Figure 3). Only Newman (2001) using naratriptan $2.5 \mathrm{mg}$ BID reported that naratriptan treated patients had fewer overall MMs and fewer MM days compared with patients in the placebo group, however no significant differences were found. The NNT for naratriptan $2.5 \mathrm{mg}$ BID was not calculated.

\section{Zolmitriptan}

Tuchman (2008), using zolmitriptan $2.5 \mathrm{mg}$ BID and TID reported that both zolmitriptan regimens demonstrated superior efficacy vs placebo, as measured by $\geq 50 \%$ reduction in the frequency of $\mathrm{MM}$ and the mean number of breakthrough MM per menstrual cycle. There were insufficient data for meta-analysis. The NNTBs for free from MM per menstrual cycle zolmitriptan $2.5 \mathrm{mg}$ BID versus placebo, $2.5 \mathrm{mg}$ TID versus placebo and $2.5 \mathrm{mg}$ TID versus BID were 4.98 (3.26 to 10.57), 2.52 (1.95 to 3.58) and 5.11 (2.95 to 18.93 ) respectively.

All studies had scores of methodological quality of $\geq 3 / 5$, and no sensitivity analysis for primary outcomes was carried out for this criterion.

\section{Secondary outcomes}

For the secondary outcomes of interest, we focused on MM severity, need for rescue medication, adverse events.

\section{Frovatriptan}

Patients with frovatriptan, both $2.5 \mathrm{mg}$ QD and BID, had a reduction in MM severity and need for rescue medication, and BID was superior to QD. Frovatriptan $2.5 \mathrm{mg}$ QD had a reduction in moderate to severe MM per PMP (0.75 [0.67 to 0.85]) giving an NNTB of 7.70 (5.43 to 13.19$)$, and in need for rescue medication per PMP (0.79 [0.70 to 0.89]) giving an NNTB of 9.28 (6.17 to 18.72) when compared with placebo. Analogously, frovatriptan $2.5 \mathrm{mg}$ BID had a reduction in moderate to severe MM per PMP (0.57 [0.50 to 0.66]) giving an NNTB of 4.43 (3.58 to 5.81), and in need for rescue medication per PMP (0.64 [0.56 to 0.74]) giving an NNTB of 5.57 (4.28 to 7.99) when compared with placebo. Frovatriptan $2.5 \mathrm{mg}$ BID vs QD had a reduction in moderate to severe MM per PMP (0.77 [0.65 to 0.90]) giving an NNTB of 10.45 (6.72 to 23.44), and in need for rescue medication per PMP (0.81 [0.70 to 0.94]) giving an NNTB of 13.93 (7.94 to 56.73) (Figure 4).

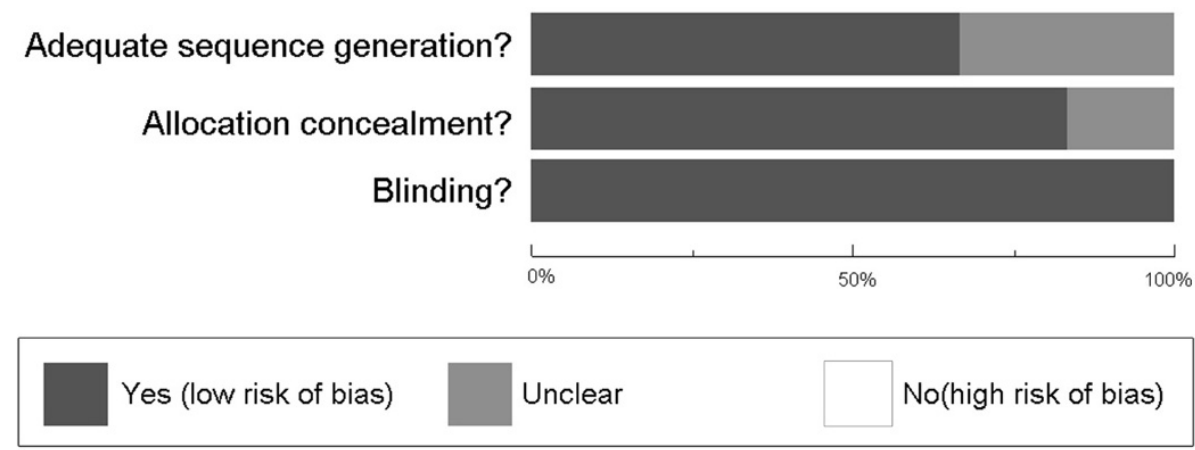

Figure 1 Methodological quality assessment: methodological quality presented as percentage across all studies. 




Figure 2 Forest plot: free from MAM per PMP in trials on frovatriptan.

The adverse events in frovatriptan $2.5 \mathrm{mg}$ QD vs placebo, frovatriptan $2.5 \mathrm{mg}$ BID vs placebo and frovatrip$\tan 2.5 \mathrm{mg}$ QD vs BID were comparable. Most reported adverse events were mild to moderate. The incidence of severe adverse events was low and appeared to be unrelated to the treatments $[7,33]$.

\section{Naratriptan}

Because the changes in MM severity and need for rescue medication were not mentioned in trails on naratriptan, we focus on adverse events and drug-related events as the secondary outcomes of trials on naratriptan. After treatment with naratriptan $1 \mathrm{mg}$ BID, there was an increase in adverse events (1.37 [1.10 to 1.70]) giving an NNTH of 10.88 (6.46 to 34.38), but drug-related events
(1.69 [0.98 to 2.90]) were comparable to the placebo (Figure 5). Newman (2001) using naratriptan $2.5 \mathrm{mg}$ BID reported that the overall adverse events and drug-related events were similar to those in placebo group. In all studies, serious drug-related adverse events were not reported $[34,35]$.

\section{Zolmitriptan}

Tuchman (2008) reported both zolmitriptan $2.5 \mathrm{mg}$ BID (0.82 [0.71 to 0.94], giving an NNTB of 7.31 [4.32 to 23.81]) and zolmitriptan $2.5 \mathrm{mg}$ TID (0.83 [0.71 to 0.97], giving an NNTB of 7.81 [4.31 to 41.64]) demonstrated a reduction in the need for rescue medication when compared with placebo.

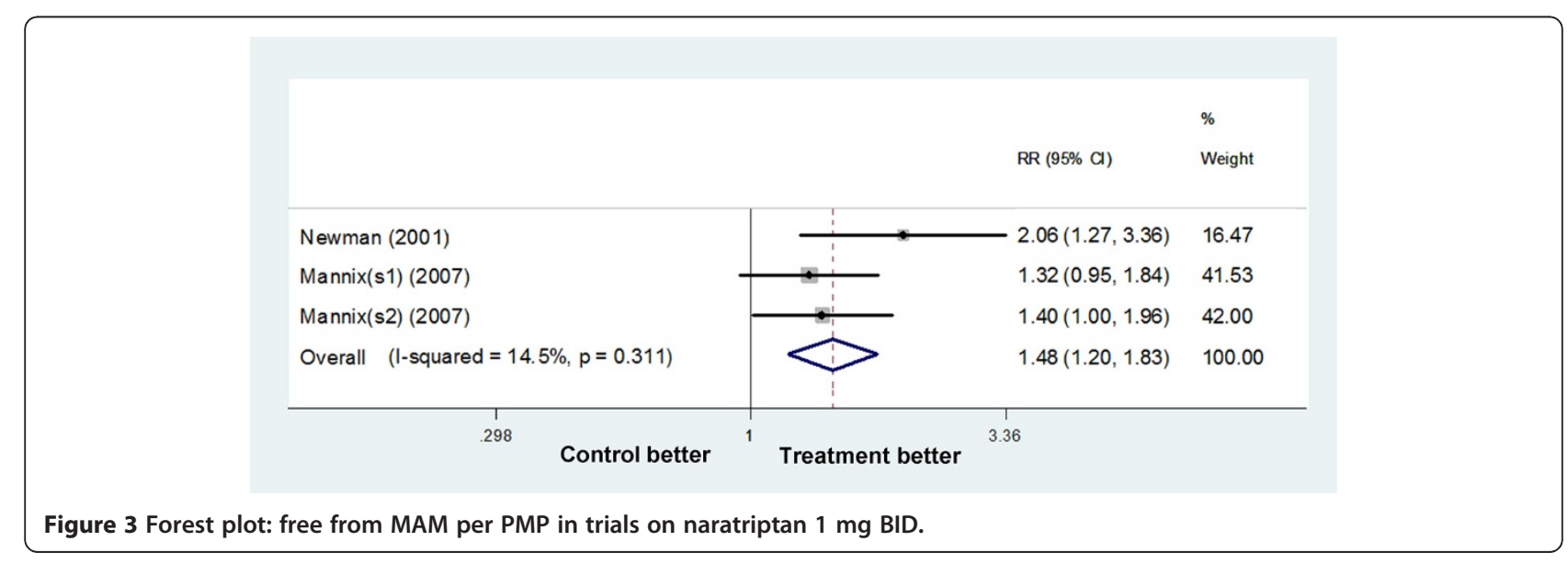




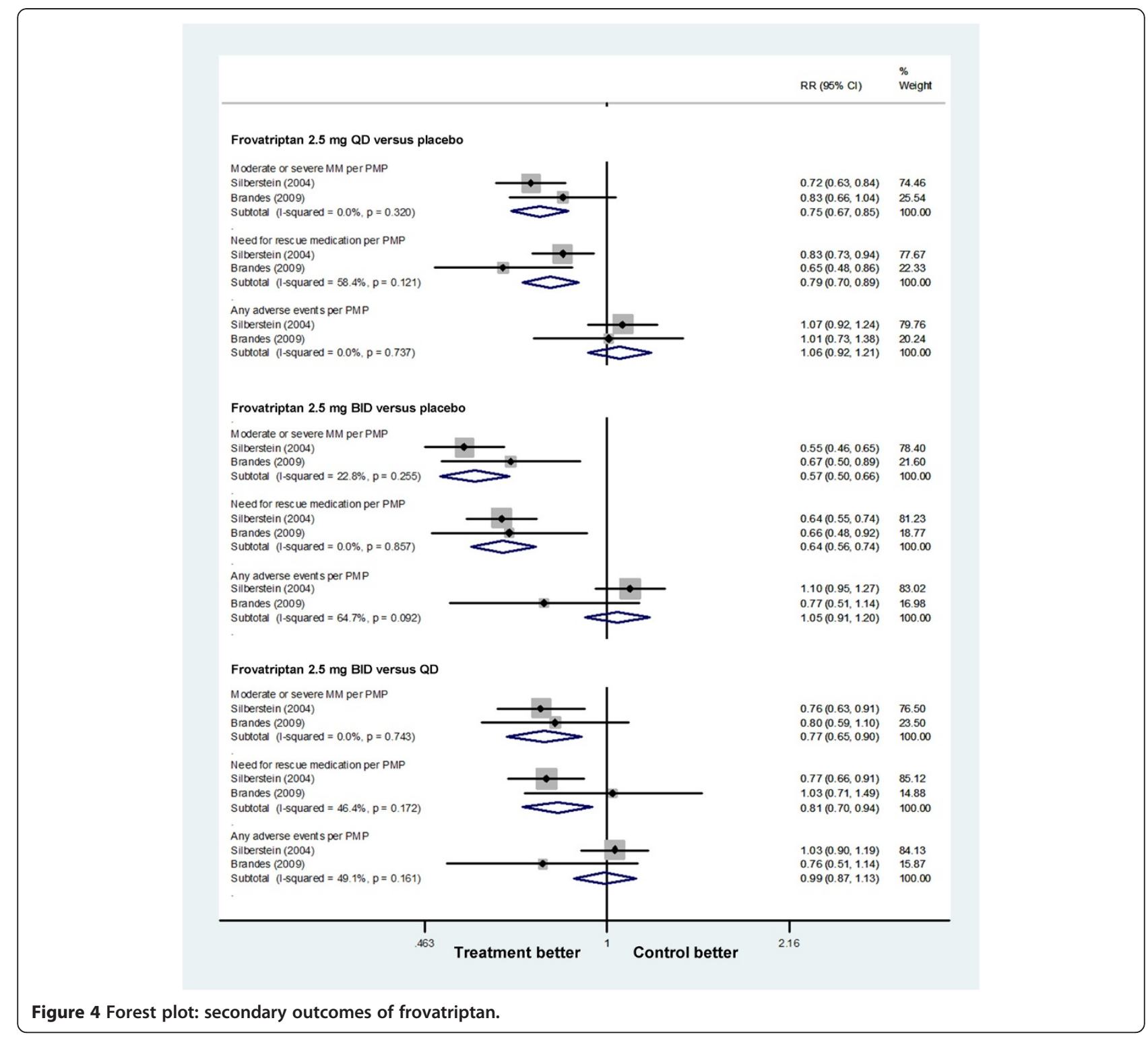

Zolmitriptan $2.5 \mathrm{mg}$ BID had an increase in any adverse event across 4 PMPs (1.44 [1.03 to 2.01]), giving an NNTH of 7.81 (4.31 to 41.64) when compared with placebo (Figure 6). Five serious adverse events were reported during the preventative therapy: two in the zolmitriptan $2.5 \mathrm{mg}$ TID group (pyelonephritis and endometrial disorder), two in the zolmitriptan $2.5 \mathrm{mg}$ BID (uterine neoplasm and anxiety) and one in the placebo group [36]. When drug-related adverse events were valued, no significant difference was found between treatment group and control group.

Data of specific adverse events was too few for analysis and was not consistently reported in these studies, so we just list the most commonly adverse events for all the three triptans in Table 2.

\section{Discussion}

\section{Summary of main results}

In this systematic review, six trials were included, and we compared the frovatriptan, naratriptan and zolmitriptan at different doses with placebo in preventing MM. We employed explicit and systematic methods to identify, select and critically appraise studies, and to extract data followed by a meta-analysis. Frovatriptan was given to 633 participants at $2.5 \mathrm{mg}$ QD and to 584 participants at $2.5 \mathrm{mg}$ BID and 646 participants were treated with placebo. Naratriptan was given to 462 participants at 1 mg or $2.5 \mathrm{mg}$ BID who were compared with 377 placebo treated participants. In addition, 80 participants received zolmitriptan $2.5 \mathrm{mg}$ BID, 83 received zolmitriptan 2.5 mg TID and 81 received placebo. In all trails, triptans 


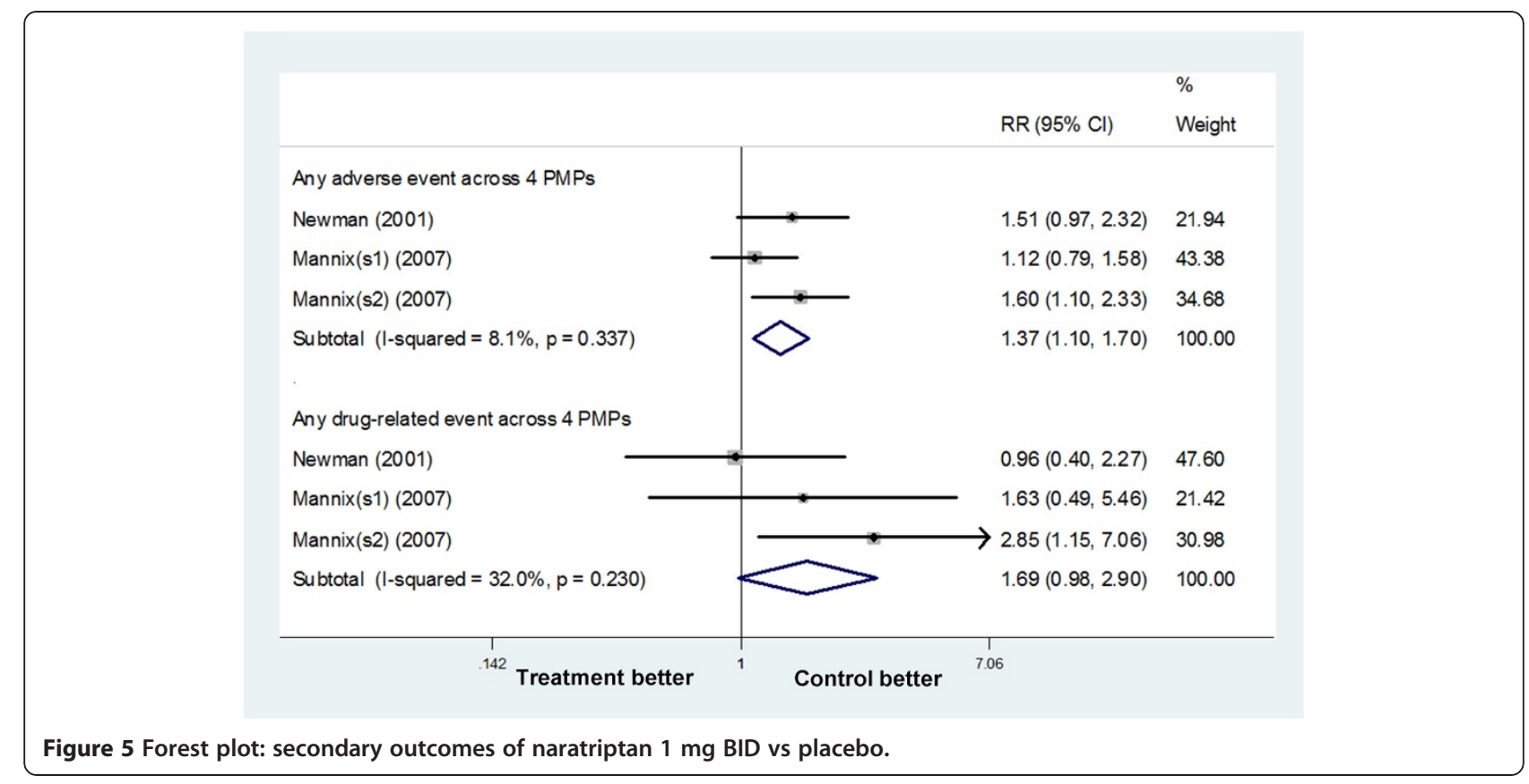

were for 5-6 days at 2-3 days before MM onset. Overall, triptans were more effective than placebo in the prevention of MM.

All of the three triptans, including frovatriptan naratriptan and zolmitriptan, were more effective than placebo in reducing the MM frequency per PMP. The incidence of moderate to severe MM per PMP and the need for rescue medication occurred less often with frovatriptan than with placebo. Patients with zolmitriptan had less need for rescue medicine than placebo treated patients. One of the putative benefits of preventative therapy for MM with triptans is to reduce the severity of MM attacks. As the NNTBs for frovatriptan $2.5 \mathrm{mg}$ BID, naratriptan $1 \mathrm{mg}$ BID, zolmitriptan $2.5 \mathrm{mg}$ TID in reducing the incidence of MM per PMP were 3.90 (3.23 to 4.93), 7.98 (5.24 to 16.71) and 2.52 (1.95 to 3.58), respectively, zolmitriptan and frovatriptan tended to be more effective than naratriptan.

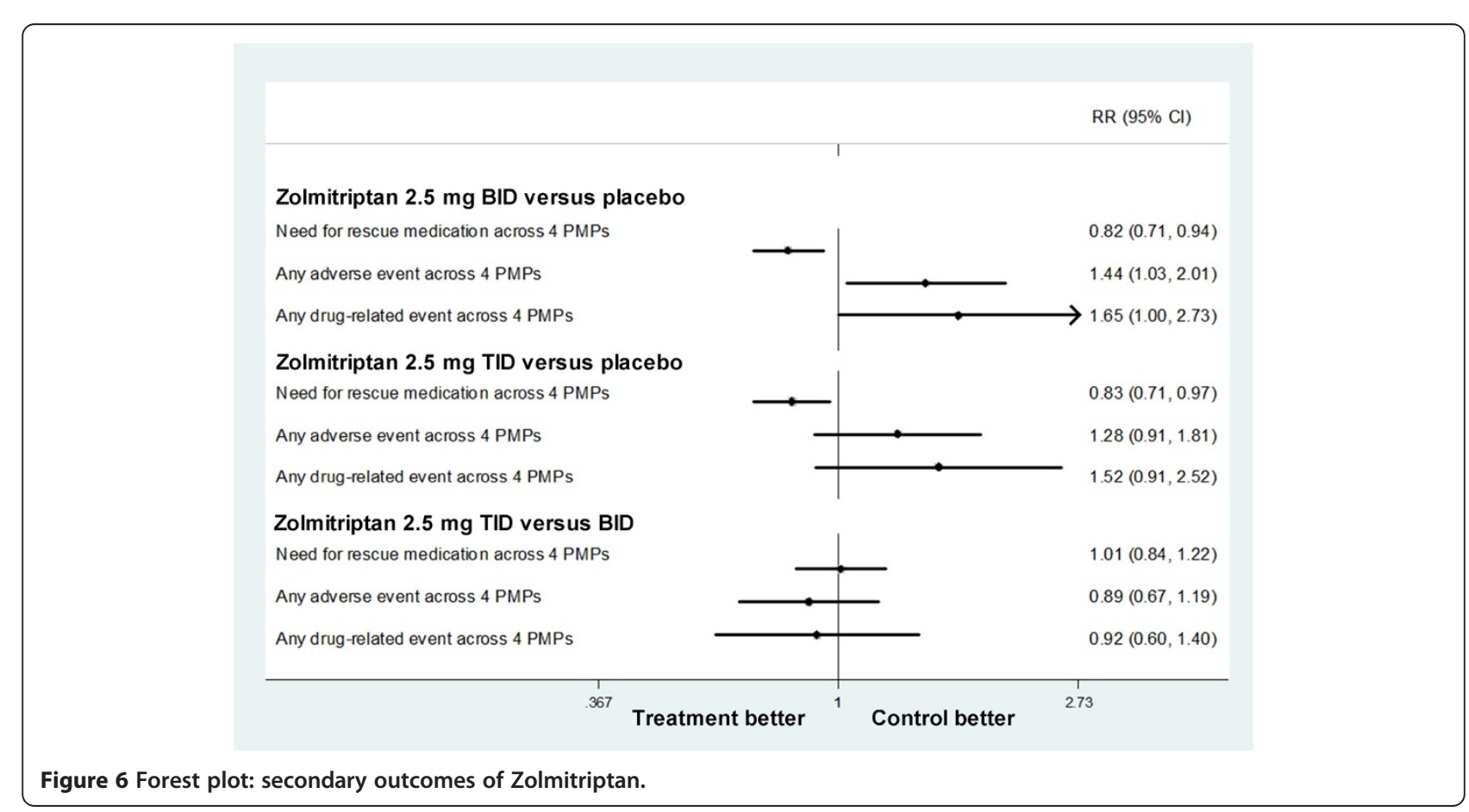


Table 2 Incidence of most commonly reported adverse events

\begin{tabular}{|c|c|c|}
\hline & Treatment & Placebo \\
\hline Frovatriptan $2.5 \mathrm{mg}$ QD & $\mathrm{n}=501$ & $\mathrm{n}=505$ \\
\hline Nausea & $4.80 \%$ & $3.40 \%$ \\
\hline Headache & $4.60 \%$ & $6.30 \%$ \\
\hline Dizziness & $3.60 \%$ & $2.60 \%$ \\
\hline Nasopharyngitis & $3.20 \%$ & $2.40 \%$ \\
\hline Dysmenorrhea & $2.20 \%$ & $3.00 \%$ \\
\hline Frovatriptan $2.5 \mathrm{mg}$ BID & $\mathrm{n}=501$ & $\mathrm{n}=505$ \\
\hline Nausea & $6.80 \%$ & $3.40 \%$ \\
\hline Dizziness & $4.80 \%$ & $2.60 \%$ \\
\hline Headache & $4.20 \%$ & $6.30 \%$ \\
\hline Nasopharyngitis & $3.40 \%$ & $2.40 \%$ \\
\hline Dysmenorrhea & $1.80 \%$ & $3.00 \%$ \\
\hline Naratriptan 1 mg BID & $n=71$ & $n=68$ \\
\hline Dyspeptic symptoms & $4.23 \%$ & $0.00 \%$ \\
\hline Malaise and fatigue & $1.41 \%$ & $2.94 \%$ \\
\hline Dizziness & $1.41 \%$ & $1.47 \%$ \\
\hline Hyposalivation & $1.41 \%$ & $0.00 \%$ \\
\hline Parasthesia & $1.41 \%$ & $0.00 \%$ \\
\hline Naratriptan $2.5 \mathrm{mg}$ BID & $n=71$ & $n=68$ \\
\hline Dizziness & $4.23 \%$ & $1.47 \%$ \\
\hline Chest symptoms & $2.82 \%$ & $2.94 \%$ \\
\hline Malaise and fatigue & $2.82 \%$ & $2.94 \%$ \\
\hline Hyposalivation & $2.82 \%$ & $0.00 \%$ \\
\hline Parasthesia & $2.82 \%$ & $0.00 \%$ \\
\hline Burning/stinging sensations & $2.82 \%$ & $0.00 \%$ \\
\hline Zolmitriptan 2.5 mg BID & $n=80$ & $n=82$ \\
\hline Asthenia & $8.75 \%$ & $9.76 \%$ \\
\hline Dizziness & $6.25 \%$ & $4.88 \%$ \\
\hline Somnolence & $6.25 \%$ & $3.66 \%$ \\
\hline Nausea & $6.25 \%$ & $1.22 \%$ \\
\hline Tightness & $5.00 \%$ & $2.44 \%$ \\
\hline Headache & $3.75 \%$ & $2.44 \%$ \\
\hline Dry mouth & $1.25 \%$ & $1.22 \%$ \\
\hline Zolmitriptan $2.5 \mathrm{mg}$ TID & $n=84$ & $n=82$ \\
\hline Asthenia & $10.71 \%$ & $9.76 \%$ \\
\hline Headache & $8.33 \%$ & $2.44 \%$ \\
\hline Dizziness & $7.14 \%$ & $4.88 \%$ \\
\hline Somnolence & $7.14 \%$ & $3.66 \%$ \\
\hline Tightness & $7.14 \%$ & $2.44 \%$ \\
\hline Nausea & $7.14 \%$ & $1.22 \%$ \\
\hline Dry mouth & $5.95 \%$ & $1.22 \%$ \\
\hline
\end{tabular}

Except frovatriptan, adverse events were more common in triptans treated patients. However, when drugrelated events were taken into account, there were no significant difference between triptans group and placebo group. Adverse events were generally mild to moderate and rarely led to withdrawal. Studies on triptan at one or two doses were underpowered for investigating the specific adverse events, and studies with longer duration are required to determine the adverse event profiles of triptans in the treatment of MM. However, the safety and tolerability of triptans in preventing migraine had been well established. Considering MM frequency and adverse events, frovatriptan $2.5 \mathrm{mg}$ BID and zolmitriptan $2.5 \mathrm{mg}$ TID are preferred for the prevention of MM.

One interesting finding was that the efficacy of triptans in prevention migraine was dependent on their concentrations. There were insufficient data to establish a clear dose-response curve. However, frovatriptan $2.5 \mathrm{mg}$ BID tended to be better than frovatriptan $2.5 \mathrm{mg}$ QD in reducing headache during PMP, and zolmitriptan $2.5 \mathrm{mg}$ TID better than zolmitriptan $2.5 \mathrm{mg}$ BID. These suggest the efficacy of triptans is concentration and timedependent. Does it mean that higher dose or frequency will bring better effect? In trials on naratriptan which has a half-time of $6 \mathrm{~h}$ [35], naratriptan $1 \mathrm{mg}$ BID was statistically superior to naratriptan $2.5 \mathrm{mg}$ BID. This implies that the efficacy of triptans in prevention of migraine depends on their concentrations. Considering that frovatriptan has a long half-life (26 h [33]) and zolmitriptan posses a short half-life ( $3 \mathrm{~h}[38])$, the frequency and dose should be adjusted when a triptan is used in the prevention of MM.

\section{Overall completeness and applicability of evidence}

Interpretation of these results is limited by the small number of studies $(n=6)$ which only included three drugs at two doses. There were inadequate numbers of participants and events to draw firm conclusions about possible differences among different drugs or doses.

Because the enlistment of trials was through clinics, this is likely to underestimate the therapeutic effect. Clinics may select participants whose MM are more severe, resistant to treatment than in the general population. On the other hand, these participants may be more motivated than the population as a whole.

In the available trials, triptans were used at safe doses while still experiencing clinically useful levels of efficacy. This may mean limitation on effective treatment; maybe combined therapy with adjunctive drugs, such as estradiol or topiramate, might increase the effectiveness.

In this review, data related to migraine attacks between menses were not identified. This overlooks the possibility, even very small, that preventative therapy 
may delay the attacks after treatment. Further studies are needed to monitor migraine attacks in menses and to establish the differences among different triptans and different doses. Long-term studies are also required to determine the safety and tolerability. Further studies comparing triptans with alternative drugs, such as estradiol or topiramate, are allowable to determine the relative benefits and harms.

The cost of triptans for MM prevention should also be taken into consideration. Each triptan is much more expensive than other prophylactic medications for migraine (such as beta blockers, tricyclic antidepressants, sodium valproate, and methysergide) [39]. At the same time, menstrual cycles have natural variability, and even in women whose menstrual cycles are regular, very few invariably attacks have associated with their periods. These infectors inevitably expose women to the use of medication during cycles in which they would not have a headache. Thus, only MM women who do not achieve adequate relief from acute therapies may become candidates for short-term preventative therapy with a triptan, particularly if they experience regular menstrual migraine attacks causing significant disability. In this way, MM attack frequency is decreased, and these patients have the opportunity to regain the days lost each month through disability.

\section{Quality of the evidence}

All studies were good in methodological quality and scored above the minimum required to minimize bias. IHS criteria or other definitions that generally conformed to IHS diagnostic criteria were used for the diagnosis of MM in all trials, and well-defined outcomes were reported for the efficacy and tolerability.

\section{Conclusion}

Current RCTs suggest that triptans treatment is an effective, short-term, prophylactic strategy for the management of MM. Considering MM frequency, severity and adverse events, frovatriptan $2.5 \mathrm{mg}$ BID and zolmitriptan $2.5 \mathrm{mg}$ TID are preferred for the treatment of MM.

\section{Competing interest}

The authors declare that there is no conflict of interest.

\author{
Authors' contributions \\ $L$ and $Y H$ designed this study. $Y H$ and $X G$ carried out the searches, \\ identified studies for inclusion and extracted relevant data. YH, XG and LF \\ were involved in analysis. $L J$ acted as arbitrator. All authors saw and \\ approved the final version.
}

\section{Open access}

This article is distributed under the terms of the Creative Commons Attribution License which permits any use, distribution, and reproduction in any medium, provided the original authors and the source are credited.

\section{Acknowledgements}

The project was supported by NSFC (81000481) and "the Fundamental Research Funds for the Central Universities" (1508219048). We thank Dr. QL Duan for critical reading of the manuscript.

Received: 10 December 2012 Accepted: 14 January 2013 Published: 30 January 2013

\section{References}

1. Brandes JL (2012) Migraine in women. Continuum (Minneap Minn) 18:835-852

2. Peng KP, Wang SJ (2012) Migraine diagnosis: screening items, instruments, and scales. Acta Anaesthesiol Taiwan 50:69-73

3. Ward TN (2012) Migraine diagnosis and pathophysiology. Continuum (Minneap Minn) 18:753-763

4. Rizzoli PB (2012) Acute and preventive treatment of migraine. Continuum (Minneap Minn) 18:764-782

5. Allais G, Castagnoli Gabellari I, De Lorenzo C et al (2007) Menstrual migraine: clinical and therapeutical aspects. Expert Rev Neurother 7:1105-1120

6. Martin VT, Lipton RB (2008) Epidemiology and biology of menstrual migraine. Headache 48(Suppl 3):S124-130

7. Brandes JL, Poole A, Kallela M et al (2009) Short-term frovatriptan for the prevention of difficult-to-treat menstrual migraine attacks. Cephalalgia 29:1133-1148

8. Headache Classification Subcommittee of the International Headache Society (2004) The international classification of headache disorders: 2nd edition. Cephalalgia 24(Suppl 1):9-160

9. Calhoun AH (2012) Current topics and controversies in menstrual migraine Headache 52(Suppl 1):8-11

10. Bussone G, Allais G, Castagnoli Gabellari I et al (2011) Almotriptan for menstrually related migraine. Expert Opin Pharmacother 12:1933-1943

11. Russell MB (2010) Genetics of menstrual migraine: the epidemiological evidence. Curr Pain Headache Rep 14:385-388

12. Colson N, Fernandez F, Griffiths $L$ (2010) Genetics of menstrual migraine: the molecular evidence. Curr Pain Headache Rep 14:389-395

13. Von Seggern RL, Mannix LK, Adelman JU (2004) Rofecoxib in the prevention of perimenstrual migraine: an open-label pilot trial. Headache 44:160-165

14. MacGregor EA, Frith A, Ellis J et al (2006) Prevention of menstrual attacks of migraine: a double-blind placebo-controlled crossover study. Neurology 67:2159-2163

15. Almen-Christensson A, Hammar M, Lindh-Astrand L et al (2011) Prevention of menstrual migraine with perimenstrual transdermal 17-beta-estradiol: a randomized, placebo-controlled, double-blind crossover study. Fertil Steril 96(498-500):e491

16. Allais G, Sanchez del Rio M, Diener HC et al (2011) Perimenstrual migraines and their response to preventive therapy with topiramate. Cephalalgia 31:152-160

17. Nelles G, Schmitt L, Humbert T et al (2010) Prevention of episodic migraines with topiramate: results from a non-interventional study in a general practice setting. J Headache Pain 11:33-44

18. Facchinetti F, Sances G, Borella P et al (1991) Magnesium prophylaxis of menstrual migraine: effects on intracellular magnesium. Headache 31:298-301

19. Giacovazzo M, Gallo MF, Guidi V et al (1993) Nimesulide in the treatment of menstrual migraine. Drugs 46(Suppl 1):140-141

20. Guidotti M, Mauri M, Barrila C et al (2007) Frovatriptan vs. transdermal oestrogens or naproxen sodium for the prophylaxis of menstrual migraine. J Headache Pain 8:283-288

21. Casolla B, Lionetto L, Candela $S$ et al (2012) Treatment of perimenstrual migraine with triptans: an update. Curr Pain Headache Rep 16:445-451

22. Tfelt-Hansen PC (2011) Published and not fully published double-blind randomised, controlled trials with oral naratriptan in the treatment of migraine: a review based on the GSK Trial Register. J Headache Pain 12:399-403

23. Sanford M (2012) Frovatriptan: a review of its use in the acute treatment of migraine. CNS Drugs 26:791-811

24. Bartolini M, Giamberardino MA, Lisotto C et al (2012) Frovatriptan versus almotriptan for acute treatment of menstrual migraine: analysis of a doubleblind, randomized, cross-over, multicenter, Italian, comparative study. J Headache Pain 13:401-406 
25. Allais G, Castagnoli Gabellari I, Mana O et al (2012) Treatment strategies for menstrually related migraine. Womens Health (Lond Engl) 8:529-541

26. Headache Classification Committee of the International Headache Society (1988) Classification and diagnostic criteria for headache disorders, cranial neuralgias and facial pain. Headache classification committee of the international headache society. Cephalalgia 8(Suppl 7):1-96

27. Tuchman M, Hee A, Emeribe $U$ et al (2006) Efficacy and tolerability of zolmitriptan oral tablet in the acute treatment of menstrual migraine. CNS Drugs 20:1019-1026

28. Facchinetti F, Allais G, Nappi RE et al (2010) Sumatriptan (50 mg tablets vs. $25 \mathrm{mg}$ suppositories) in the acute treatment of menstrually related migraine and oral contraceptive-induced menstrual migraine: a pilot study. Gynecol Endocrinol 26:773-779

29. Savi L, Omboni S, Lisotto C et al (2011) Efficacy of frovatriptan in the acute treatment of menstrually related migraine: analysis of a double-blind, randomized, cross-over, multicenter, Italian, comparative study versus rizatriptan. J Headache Pain 12:609-615

30. Brandes JL, Smith T, Diamond M et al (2007) Open-label, long-term tolerability of naratriptan for short-term prevention of menstrually related migraine. Headache 47:886-894

31. Jadad AR, Moore RA, Carroll D et al (1996) Assessing the quality of reports of randomized clinical trials: is blinding necessary? Control Clin Trials 17:1-12

32. Brigo F, Storti M, Nardone R et al (2012) Transcranial magnetic stimulation of visual cortex in migraine patients: a systematic review with meta-analysis. $J$ Headache Pain 13:339-349

33. Silberstein SD, Elkind AH, Schreiber C et al (2004) A randomized trial of frovatriptan for the intermittent prevention of menstrual migraine. Neurology 63:261-269

34. Newman L, Mannix LK, Landy S et al (2001) Naratriptan as short-term prophylaxis of menstrually associated migraine: a randomized, double-blind, placebo-controlled study. Headache 41:248-256

35. Mannix LK, Savani N, Landy S et al (2007) Efficacy and tolerability of naratriptan for short-term prevention of menstrually related migraine: data from two randomized, double-blind, placebo-controlled studies. Headache 47:1037-1049

36. Tuchman MM, Hee A, Emeribe $U$ et al (2008) Oral zolmitriptan in the shortterm prevention of menstrual migraine: a randomized, placebo-controlled study. CNS Drugs 22:877-886

37. Silberstein SD, Berner T, Tobin J et al (2009) Scheduled short-term prevention with frovatriptan for migraine occurring exclusively in association with menstruation. Headache 49:1283-1297

38. Lionetto L, Casolla B, Mastropietri F et al (2012) Pharmacokinetic evaluation of zolmitriptan for the treatment of migraines. Expert Opin Drug Metab Toxicol 8:1043-1050

39. Loder E (2002) Prophylaxis of menstrual migraine with triptans: problems and possibilities. Neurology 59:1677-1681

doi:10.1186/1129-2377-14-7

Cite this article as: Hu et al:: Triptans in prevention of menstrual migraine: a systematic review with meta-analysis. The Journal of Headache and Pain 2013 14:7.

\section{Submit your manuscript to a SpringerOpen ${ }^{\circ}$ journal and benefit from:}

- Convenient online submission

- Rigorous peer review

- Immediate publication on acceptance

- Open access: articles freely available online

- High visibility within the field

- Retaining the copyright to your article

Submit your next manuscript at $\gg$ springeropen.com 